\title{
An Energy Market Model for Homes with Battery Energy Storage and Solar Photovoltaic Systems: A Case Study
}

\author{
Mohamed F. Abdel-Fattah ${ }^{1, \text { * }}$, Josef Punt ${ }^{1,2}$ \\ ${ }^{1}$ School of Science and Engineering, Reykjavik University, Reykjavik, Iceland \\ ${ }^{2}$ Department of Electrical and Computer Engineering, Technical University of Munich, Munich, Germany
}

Email address:

abdelfattah $@$ ru.is (M. F. Abdel-Fattah), josef.punt $a$ tum.de (J. Punt)

${ }^{*}$ Corresponding author

\section{To cite this article:}

Mohamed F. Abdel-Fattah, Josef Punt. An Energy Market Model for Homes with Battery Energy Storage and Solar Photovoltaic Systems: A Case Study. International Journal of Energy and Power Engineering. Vol. 8, No. 5, 2019, pp. 66-72. doi: 10.11648/j.ijepe.20190805.11

Received: September 25, 2019; Accepted: October 23, 2019; Published: November 8, 2019

\begin{abstract}
The energy market is tending to be more flexible and therefore the price range of energy might vary a lot over the day. As a result, it might be feasible to consider energy storage systems for private households. This paper presents an average Ontario household case study that will be evaluated on an economical basis. The integration of energy storage systems has many advantage and could play an important role in smart-grids technology. Energy storage systems could save the energy cost depending on the dynamic price levels and also form solar PV panels if available. The presented work in this paper started from a simple basic analysis, presented a simple algorithm, and investigated the economic aspect possibilities. Adding energy storage system to household case is considered at the beginning. Then, the work has been extended to consider the integration of the solar photovoltaic panels/system which is presenting an advanced system which is very interesting to investigate. Also, the savings from self-generated energy, for the considered case study is presented. Finally, the current situation is evaluated and the suggested solutions and possibilities are presented. The role the technology role in the system cost and saving is confirmed and, up to now, the subventions for solar PV systems is still expected for economic feasibility.
\end{abstract}

Keywords: Energy Storage Systems (ESS), Battery Technologies, Solar Photovoltaic (PV), Systems and Household Case Study

\section{Introduction}

Since the energy market is tending to get more flexible and therefore the price range of energy over time varies a lot, it is interesting to consider energy storage systems for private households. Many research papers have been focused on using an energy storage system (ESS) as an add-on to a household that should cover its energy needs from solar PV panels [1].

The main challenge now is the cost of solar PV panels when compared to the energy saving cost. The benefits of the ESS is undeniable, and the main goal is to minimize the cost of consumed energy. Furthermore, on the other (utility) side, it could help by shifting the peak load period. Pumped-hydro energy storage is the oldest type and the most efficient ESS available nowadays. However the required space and startup cost of the structure is not feasible for a residential size household.
Some papers, as in [2], offer an excellent guideline when it comes to choosing a proper battery size that depends on the size of solar panels and energy and market fluctuations. Energy Storage Systems are not limited only to lead acid batteries, there are multiple other technologies that are used depending on the scale, required response, capacity and maintenance [3]. Some scenarios also propose using electric car batteries when needed.

This paper presents a developed energy market model for homes with battery energy storage and additional solar photovoltaic (PV) systems based on the case study presented in [4]. The model is developed for energy flow simulation with economic analysis. Long term energy market, solar and consumption data are used to simulate different cases. The main object, of this paper, is to present the economic analysis for an average household including an installed energy storage system (ESS) and solar PV panels.

An optimization framework is proposed [5], for finding 
optimal operation rule-based strategies for operating an energy storage device connected to a self-use solar generation system for minimizing the payments to the grid using real data for solar generation and building load, and it is found that they are able to achieve near-optimal performance without requiring forecasts. A graphical, performance-based energy storage capacity sizing method [6] is proposed for residential loads with high solar penetration levels, using the calculated rated power and storage capacity of an energy storage device. The historical solar radiation data, residential household load data, and residential load models are used for creating the net load, considering the solar generation.

The importance of an intelligent battery control, in combination with solar generation, is presented [7] which confirmed that it could increase renewable uptake and also reducing electricity bills without interrupting daily life scenario of the customers. The demand response is applied with efficient and specific control of domestic appliances through load shifting and curtailment. A scenario-based stochastic optimization approach [8] is applied in the energy scheduling problem of smart homes to address the variability and uncertainty issues of the PV panels. A combination of genetic algorithm and linear programming is applied as the optimization tool for the energy scheduling problem, and considering generation scheduling and unit commitment problems.

\section{Analysis of Different Model Components}

The case study is defined as the province of Ontario in Canada, and Ottawa is chosen because of the availability of good solar data [9]. The local currency, used, is the Canadian dollar (CAD) in which all financial calculations will be done. For the considered economic analysis, a yearly analysis is conducted without taken interests into account.

\subsection{Energy Market}

Different approaches can be used for the energy market analysis like flat, time of use (TOU) or energy market pricing. The energy market is tending to be more flexible. The price-controlled consumption model is developed based on the hourly Ontario energy pricing (HOEP) from the independent electricity system operator and also the TOU pricing is considered [10]. The daily distribution of the HOEP data can be seen in Figure 1. The mean pricing value of year 2016 is $0.0152 \mathrm{CAD} / \mathrm{kWh}$. For the TOU pricing, the values are displayed in Figure 2. The considered load curve is also shown in Figure 3.

\subsection{Energy Consumption}

For the considered case study, in [4], the monthly energy consumption is $750 \mathrm{kWh}$ corresponded to a load of $25 \mathrm{kWh}$ per day, as distributed like shown in Figure 3. We assume that no heating nor cooling is done with electricity so the load profile for winter equals the load profile for summer. Given this prerequisites, the annually energy price directly from the grid is the simple multiplication of the daily load as shown in Figure 3 times the hourly average price as shown in Figure 1. The results are $165.75 \mathrm{CAD} / \mathrm{a}$ for the year 2016 for HOEP (pure energy price) and a calculated value of $1039.3 \mathrm{CAD} / \mathrm{a}$ for the TOU pricing.

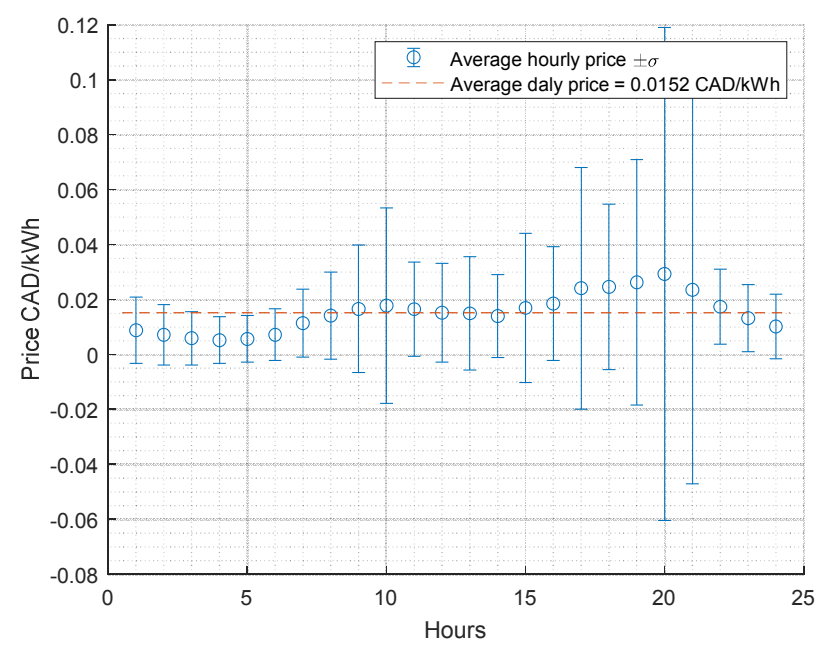

Figure 1. HOEP for 2016.

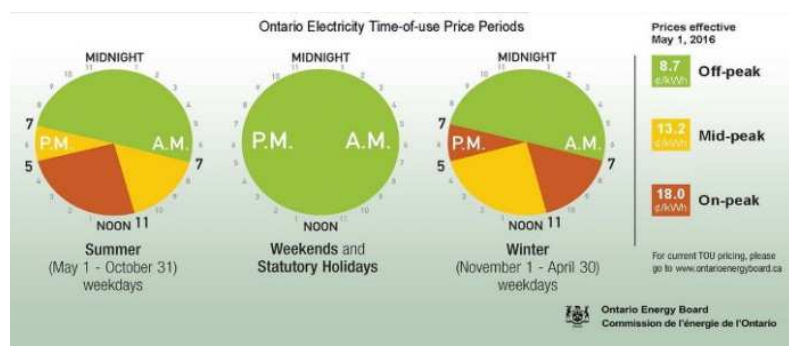

Figure 2. TOU-pricing [4].

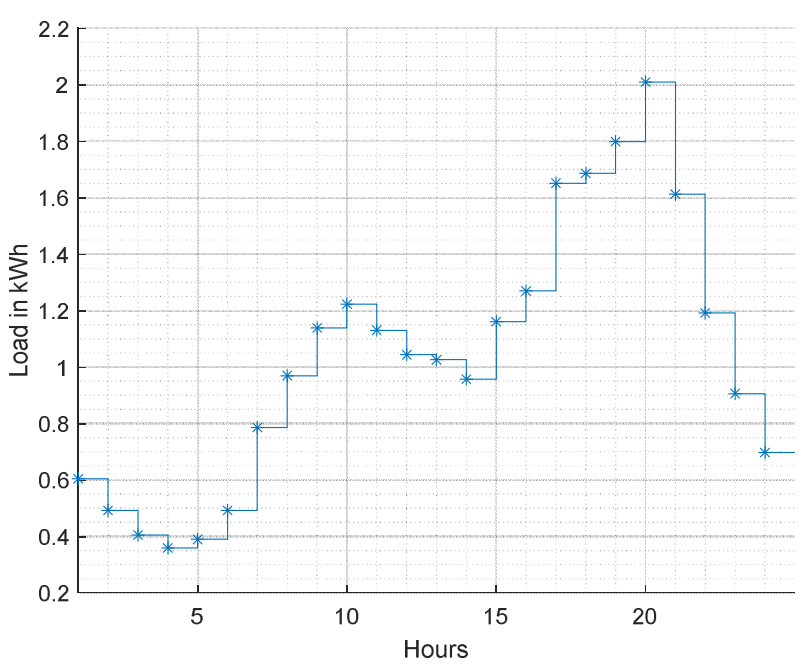

Figure 3. Load curve.

Additional to the energy price, some fees such as delivery and regulatory charges are mandatory.

1. Annual Energy, HOEP: 165.75 CAD

2. Monthly delivery: 51.25 CAD

3. Monthly regulatory Charges: 5.54 CAD 


\section{Annual Total: 847.23 CAD}

In the following cases, all models assume available access to the energy market. For further analysis, the delivery and regulatory charges are neglected. The previous values will be considered for economic benefits.

\subsection{Energy Storage System (ESS)}

Many different battery types are available on the market. Considering a stationary battery storage, the weight and volume are not as important, to consider, as the long lifetime and low price. For a long-term economic approach, the annual battery costs are calculated. They are strongly depend on calendar and cyclic aging. To simplify analysis, it is assumed that the battery will be cycled once a day which correspond to 365 cycles/year. Considering this average cycling time for the battery type, it is important to consider both of the calendar and cyclic aging. The common battery technologies for such applications are Lead-Acid, Ni-Cd, and Lithium-based [11]. Despite that the Lead-Acid is among the cheapest systems for initial investment in annual model, the research shows that it gets beaten by Lithium based models due to their longer lifetimes [12]. Also the Lead-Acid Batteries may require maintenance which presents more difficulties.

Among the different types of Lithium-based battery systems, the LFP technology has the highest economic benefit [13].

The optimal battery size is found to be round $4 \mathrm{kWh}$ for a daily consumption of $25 \mathrm{kWh}$ and the maximum discharge power is $2 \mathrm{~kW}$ [4].

Based on these results, for a battery size of $2 \mathrm{kWh}$, and bigger, the maximal discharge rate is $1 \mathrm{C}\left(\mathrm{C}_{\mathrm{N}}\right.$ (Nominal capacity $/ \mathrm{h}$ ) which corresponds to a full discharge of the battery within one hour, or lower.

This can easily be handled by the lithium iron phosphate (LFP) battery technology. Regarding the charging process, since hourly pricing is used, the worst case is to load the battery with a $1 \mathrm{C}$ rate which is also could be handled by LFP battery technology.

Different battery types have different characteristics which are briefly summarized in Table 1, including min, median and max values for lifetime assumptions [14].

The annually cost for the ESS could be calculated, for an optimal case, using data in Table 1 [4], and (1)-(3). Some results are presented in Table 2 . To estimate the annual costs, the self the life duration of the battery needs to be calculated at the beginning.

As one cycle per day is assumed for the battery, and hence the corresponding life time ( $T$ in years) is calculated using (1). Given the Lifetime $(T)$, the annual costs for the battery and ESS system ( $\operatorname{Cost}_{B A T T / a}$ and $\left.\operatorname{Cost}_{E S S / a}\right)$ could be calculated using (2) and (3) respectively.

The rated System cost, per power, are multiplied by the total installed power energy $\left(E_{\text {Batt }}\right)$ and then divided by the lifetime $(T)$ and finally the cost is converted from Euro to CAD, using 1.5 exchange rate.

$$
\begin{aligned}
\mathrm{T}= & (5325 \text { cycles }) /(356 \text { cycles } / \mathrm{a})=14.6 \mathrm{a} \\
\text { Cost }_{\mathrm{BATT} / \mathrm{a}} & =309 € / \mathrm{kWh} \times 1.5 \mathrm{CAD} / € \times \mathrm{E}_{\text {Batt }} / \mathrm{T} \\
\text { Cost }_{\mathrm{ESS} / \mathrm{a}} & =1027 € / \mathrm{kWh} \times 1.5 \mathrm{CAD} / € \times \mathrm{E}_{\mathrm{Batt}} / \mathrm{T}
\end{aligned}
$$

\subsection{Solar Panel as Additional Power Source}

The next step for building a more advanced and efficient system model is achieved by adding a solar PV panel. According to the nominal installed power and the available solar data [9], the total generation is calculated. For the installation cost of the solar panel, a price of $4 \mathrm{CAD} / \mathrm{W}$ is assumed [15]. For the lifetime, 25 years are assumed, as in [16]. Based on these assumptions, the annual price over the

\begin{tabular}{|c|c|c|c|c|c|c|}
\hline Component & LFP & LMO & NCA & NMC & $\mathrm{NaNiCl}$ & VRLA \\
\hline Cell Cost $[€ / \mathrm{kWh}]$ & 309 & 238 & 213 & 318 & 220 & 230 \\
\hline System Cost [€/kWh] & 1027 & 946 & 906 & 1001 & 941 & 1171 \\
\hline Cycles min & 1750 & 1000 & 1250 & 1000 & 1000 & 300 \\
\hline (a) DoD med & 5000 & 1500 & 3000 & 4000 & 3000 & 1400 \\
\hline $80 \% \max$ & 5325 & 5000 & 5125 & 4875 & 6250 & 1600 \\
\hline Efficiency [\%] & 96 & 94 & 91.5 & 94 & 86 & 76.5 \\
\hline Time $[\mathrm{a}]$ med & 15 & 10 & 10 & 10 & 14 & 18 \\
\hline $\max$ & 20 & 15 & 20 & 20 & 14.8 & 20 \\
\hline
\end{tabular}
installed size evolves as shown in Table 3.

Table 1. Batteries Techno-Economic Performance Data [14].

Table 2. ESS Cost Over Size.

\begin{tabular}{lllllll}
\hline $\mathbf{E}_{\text {batt }}[\mathbf{k W h}]$ & $\mathbf{2}$ & $\mathbf{4}$ & $\mathbf{6}$ & $\mathbf{8}$ & $\mathbf{1 0}$ & $\mathbf{1 2}$ \\
\hline $\mathrm{C}_{\text {annual, BATT }}[\mathrm{CAD}]$ & 63 & 127 & 190 & 254 & 317 & 381 \\
$\mathrm{C}_{\text {annual, SYs }}[\mathrm{CAD}]$ & 211 & 422 & 633 & 845 & 1055 & 1267 \\
\hline
\end{tabular}

Table 3. Solar System Cost Over Size.

\begin{tabular}{lllllll}
\hline $\mathbf{P}_{\mathbf{N}}[\mathbf{k W}]$ & $\mathbf{2}$ & $\mathbf{4}$ & $\mathbf{6}$ & $\mathbf{8}$ & $\mathbf{1 0}$ & $\mathbf{1 2}$ \\
\hline Price $[\mathrm{CAD}]$ & 320 & 640 & 960 & 1280 & 1600 & 1920 \\
\hline
\end{tabular}

\section{Algorithm Analysis}

\subsection{Cost Calculations}

The total annual energy cost $\left(\right.$ Cost $\left._{\text {TOTAL/a }}\right)$, in (7), could be calculated by adding the total energy consumed ( Cost $_{\text {POWER/a }}$ ), in (4), to the cost of the ESS (Cost ESS $/ a)$, in (5), and the cost of the solar PV panel $\left(\right.$ Cost $\left._{\text {SOLAR/a }}\right)$, in (6) if considered. 


$$
\begin{gathered}
\text { Cost }_{\text {POWER } / \mathrm{a}}=\int \mathrm{C}_{\text {POW }}(\mathrm{t}) * \mathrm{P}(\mathrm{t}) \mathrm{dt} \\
\text { Cost }_{\mathrm{ESS} / \mathrm{a}}=105 \mathrm{CAD} / \mathrm{kWh} \\
\operatorname{Cost}_{\mathrm{SOLAR} / \mathrm{a}}=160 \mathrm{CAD} / \mathrm{kW} \\
\text { Cost }_{\mathrm{TOTAL} / \mathrm{a}}=\mathrm{C}_{\text {POWER } / \mathrm{a}}+\mathrm{C}_{\mathrm{ESS} / \mathrm{a}}+\mathrm{C}_{\text {SOLAR } / \mathrm{a}}
\end{gathered}
$$

For a comparison, we use the energy cost from 2016 with given load profile, without ESS nor solar PV panel, by taking the power directly from the grid which corresponds to 165.75 CAD for direct market access or 1039.3 CAD for TOU pricing. For the following analysis the energy market-/solar- data from 2016 and 2017 are used and divided by two to get the annual average.

\subsection{The Algorithm}

The calculations are done in a simplified way where the total battery energy will be loaded according at the price minima of the day and discharged during the maximal priced hours of the same day. The procedure is graphically explained in Figure 4, for the $28^{\text {th }}$ of June 2016. At the daily price minima, the full batter energy is loaded and then discharged over the maximal priced hours which result in a new battery optimized grid load under Figure 4 (c). After the integration of the solar PV system into the full system, the solar PV generation shown in Figure 4 (d) will be subtracted from the optimized battery-grid load and the results for the final grid load is shown in Figure 4 (e). In case of energy overproduction, it will be sold to the grid with the current market price. The price data is calculated using the final grid load.

\subsection{The Results}

The annual total costs, calculated using (7), with different ESS/battery sizes are shown in Figure 5, where the red and blue line represent the annual cost without any system, for the considered test case energy market prices.

For the household with only a solar PV system, the annual costs are shown in Figure 6. After integrating the ESS system with the solar PV panel system, the results are shown in Figure 7 and Figure 8 are obtained. Where first the grid load curve is calculated using the daily consumption and dis/charge optimization of the ESS and considering the solar production.

These results show that for the price of the ESS and solar PV panels with HOEP pricing, the economical profit is not achieved. However with TOU pricing, it could be achieved until reaches a nonprofit point, as shown in Figure 6.

Generally, the performance of the systems with solar PV panels is better than a standalone ESS systems.

This is mainly due to the saving from selling the overproduction in the energy from the solar PV panels to the grid with the market prices. Since the market prices of energy in TOU pricing is about 10 times higher than HOEP pricing, a lot of money could be earned which compensates the investment costs of the solar PV panels.
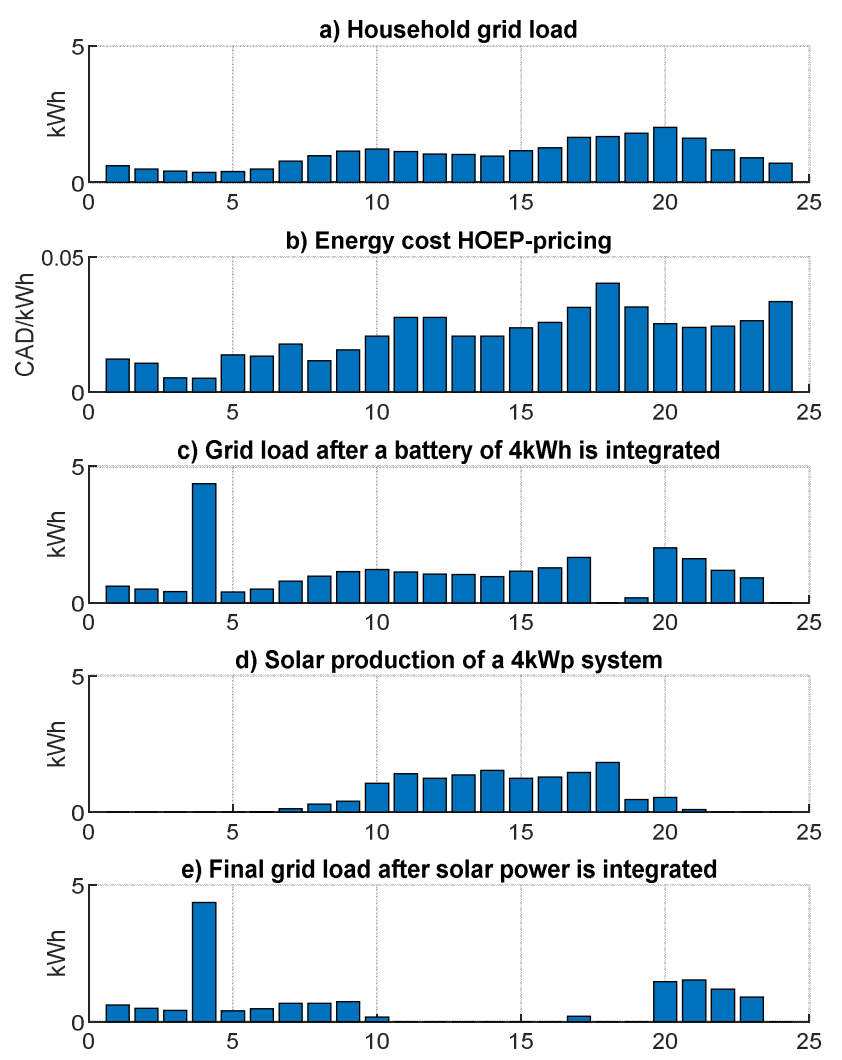

Figure 4. Optimization algorithm step by step.

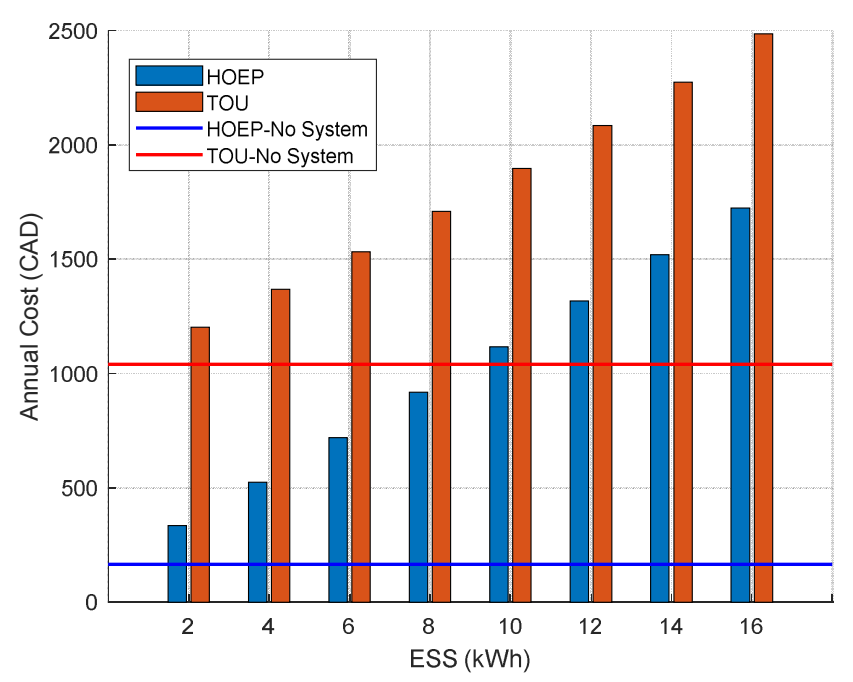

Figure 5. Annual costs with different ESS systems.

\section{Breakeven Point Evaluation}

The results confirm the saving by the installation of an ESS system by buying cheaper electricity however the saving is still not enough for covering the installation costs. For the approaches above to be economically feasible, either the system costs need to be much lower or the market prices of energy needs to be higher. Assuming the same, considered, market prices then the system costs could be economically feasible if the costs could be less than the savings obtained by the ESS, shown in Figure 9. 


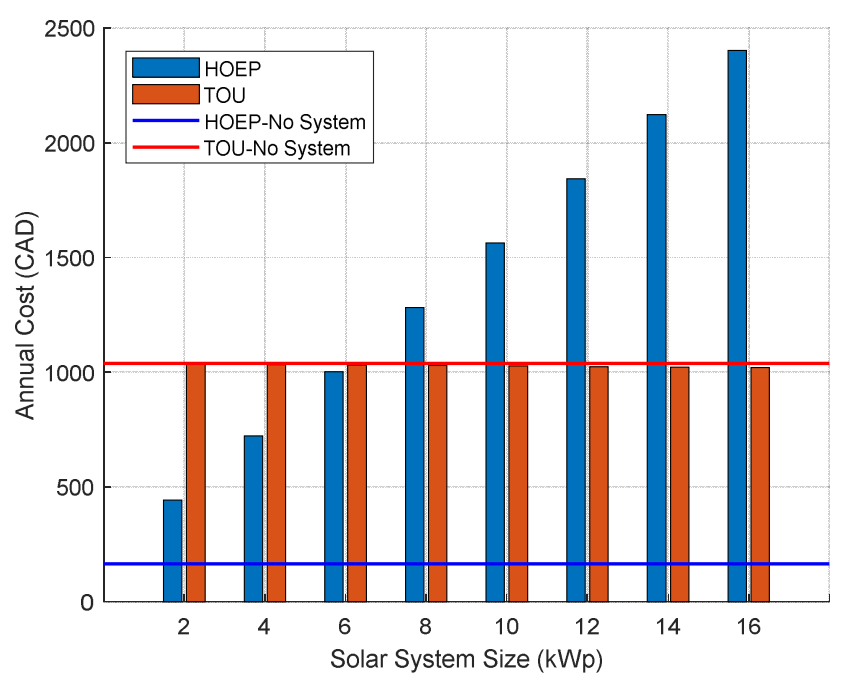

Figure 6. Annual costs with different solar PV systems.

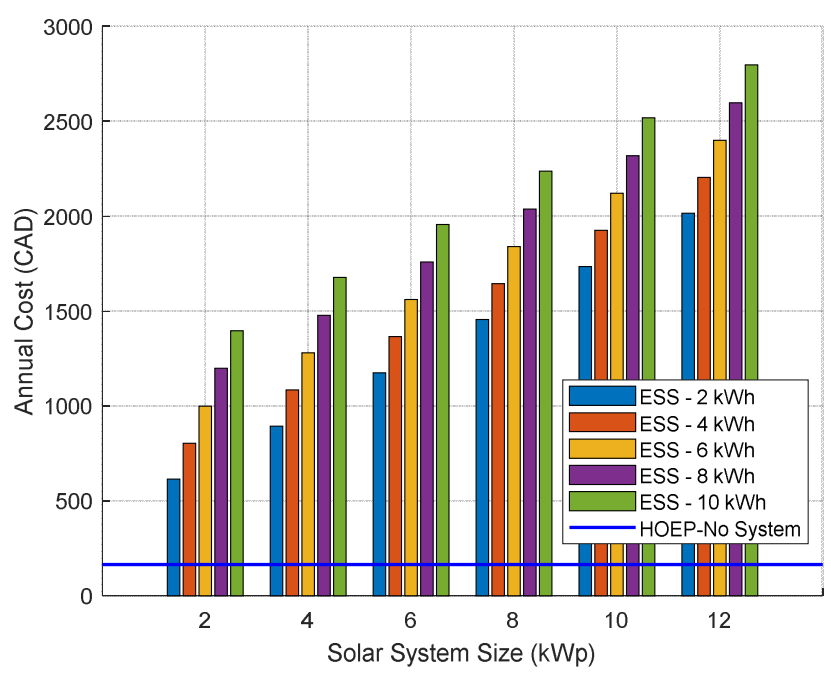

Figure 7. Annual costs for combined systems with HOEP pricing.

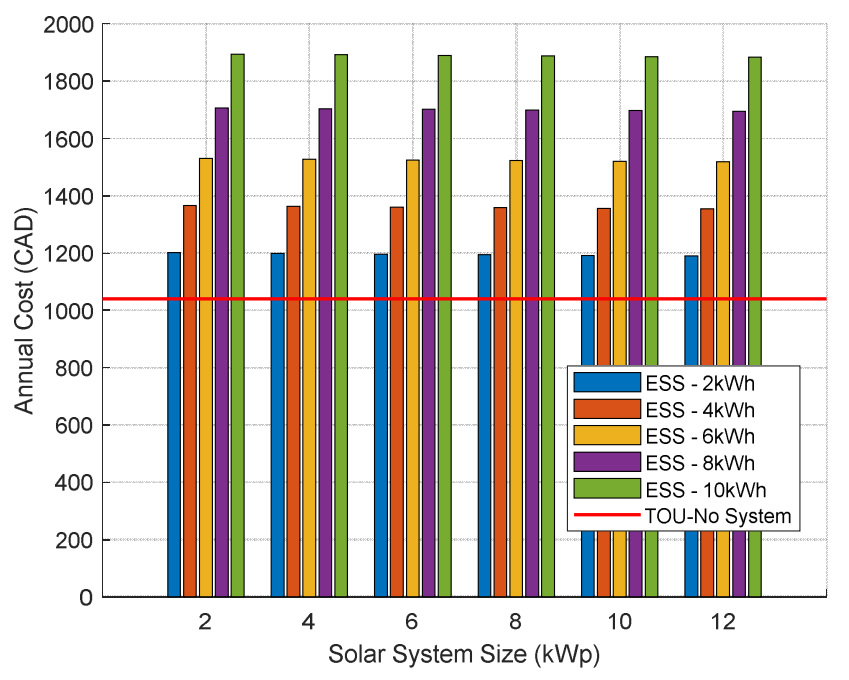

Figure 8. Annual costs for combined systems with TOU pricing.

This would mean, that the annually cost for the system needs to be less than about $21 \mathrm{CAD} / \mathrm{kWh}$ which by state-of-the-art technology cannot be reached.
Further analysis are considered here to highlight the breakeven point for costs to be economically feasible. This could be done by scaling, increasing few times, the market pricing, instead of the system costs. The solar PV and ESS systems will be considered separately.

It is found that the breakeven point for the solar PV system could be reached when the HOEP pricing are scaled, increased, by a factor of 8 . With the TOU pricing, the breakeven point is already reached. The scaled prices for the solar PV system, needed for reaching the feasible breakeven points, are presented in Figure 10.

For the ESS system, it is found that the breakeven point could be reached when the HOEP price is scaled, increased, by a factor of 6 and the TOU price is scaled, increased, by a factor of 5. The scaled prices for the ESS system, needed for reaching the feasible breakeven points, are presented in Figure 11. Although the scaling for TOU price is smaller in means but with a high no-system cost of about 5196 CAD annually. However, the HOEP price is scaled by a factor of 6 with just about 995 CAD no-system annual costs. This is still much if compared to the HOEP price of 165.7 CAD annually but still less than the standard TOU price.

For the combined system of ESS and solar PV, the scaling values are highly depended on the used optimization algorithm and the market buy/sell conditions.

\section{Hoep Scaled to Tou Pricing}

\subsection{Approach of Scaling HOEP to TOU Pricing}

The saving with ESS system could be achieved in case of high variation in the energy market prices. The market TOU pricing has an appropriate pricing scale and also the HOEP pricing has this variation characteristics but with a lower total average scale, in the considered test case.

By assuming a market with HOEP pricing model that will be scaled by a factor of 6.27 , we could reach an energy price of 1039.3 CAD annually with no-system, which is the same value for the TOU pricing. The cost results for this approach are shown in Figure 12, after scaling HOEP to TOU pricing.

\subsection{The Results}

Therefore, Figure 8 presents the results for a combined system with TOU pricing and Figure 12 presents the results for a combined system with the corresponding scaled HOEP pricing. The results are different despite the fact that both have the same energy price value with no-system present. These results confirm the great effect of the market conditions on the economic analysis. In fact, this could be considered an important conclusion from this work which was not expected. Unfortunately, it seems not possible to promote solar PV and/or ESS systems only by changing the market conditions but it is found that changing the energy price for a nonhousehold system is essential. 


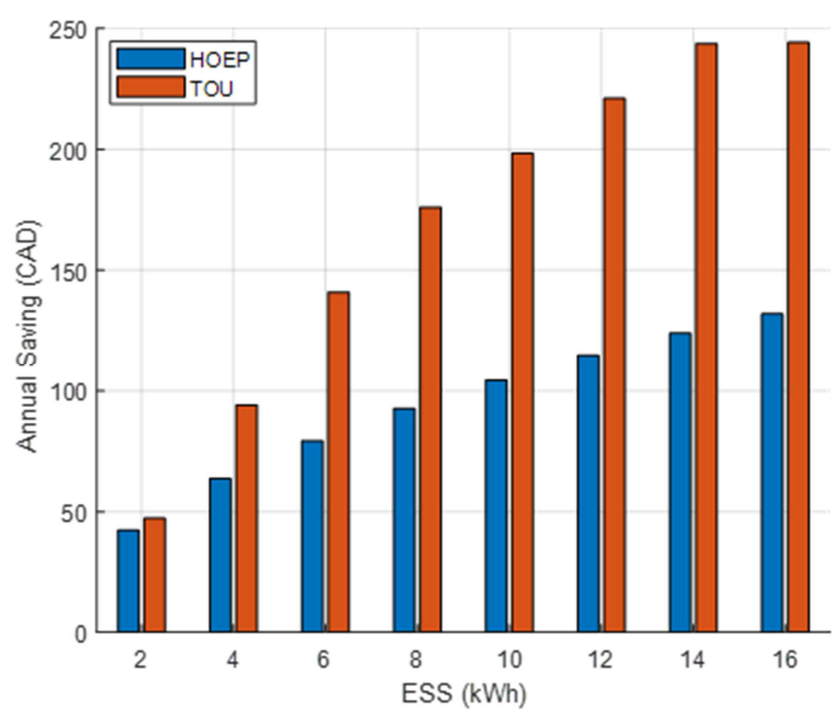

Figure 9. Annual savings after integrating different ESS systems.

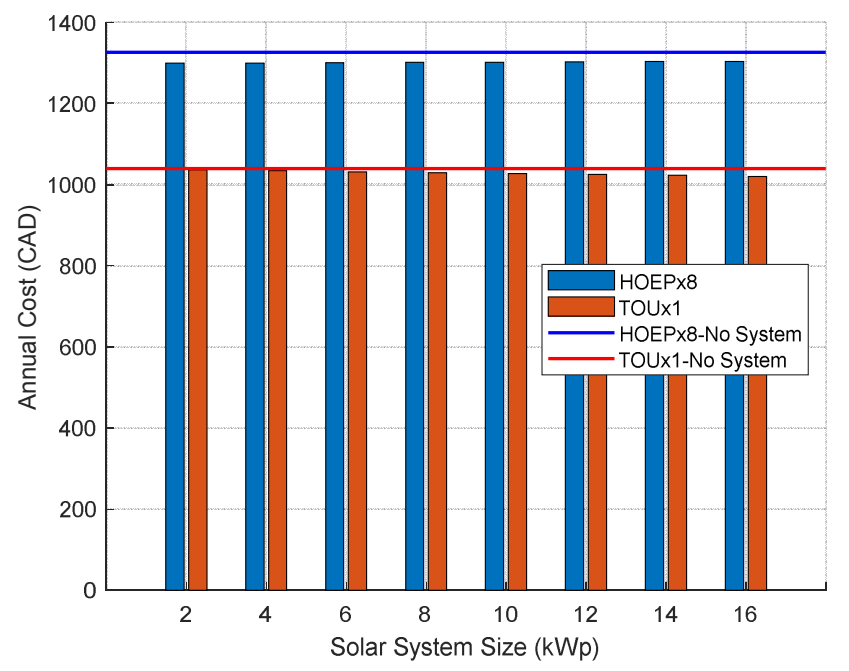

Figure 10. The scaled prices for the solar PV system.

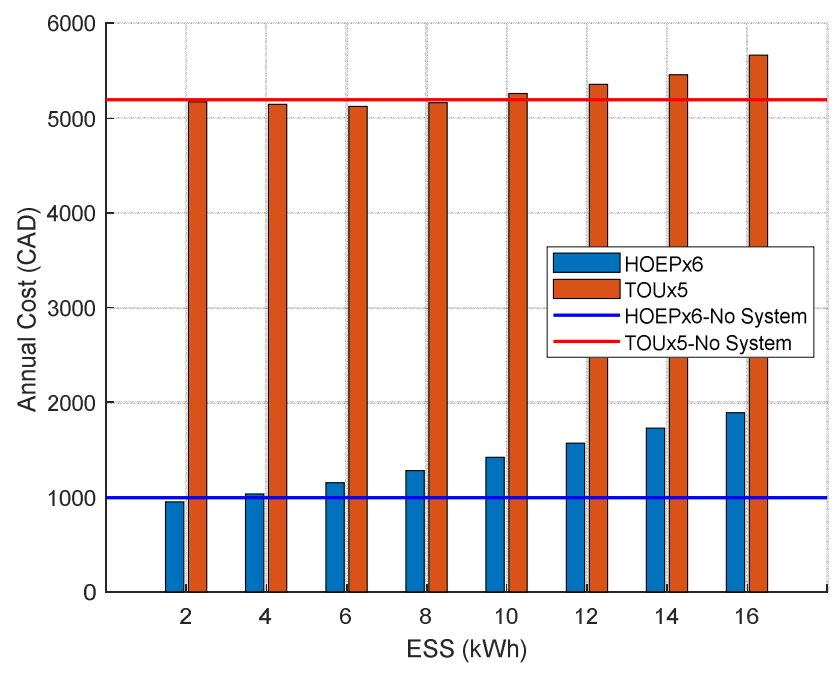

Figure 11. The scaled prices for the ESS system.

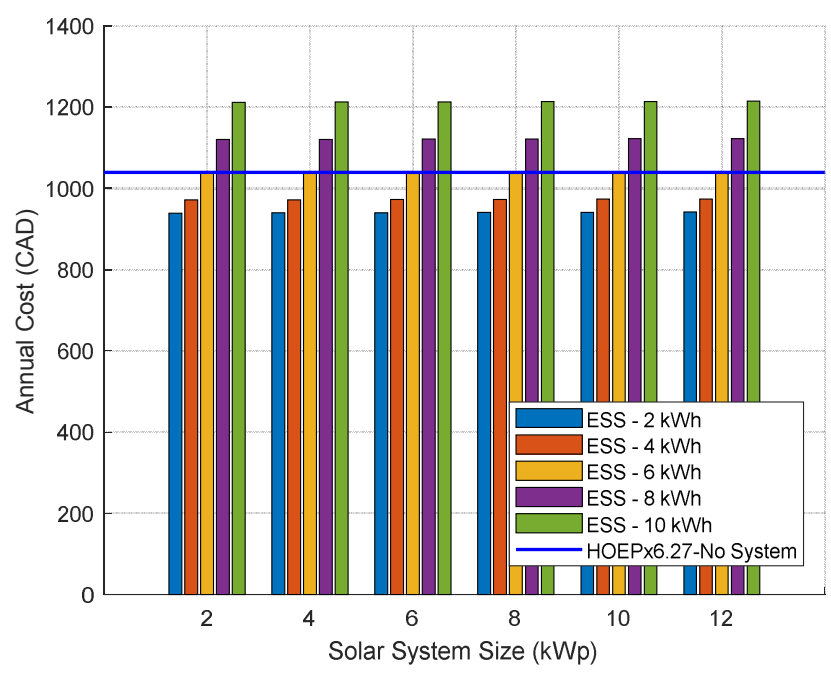

Figure 12. The cost results after scaling HOEP to TOU pricing.

\section{Discussion}

\subsection{ESS Systems}

The ESS systems could be profitable if the annual energy savings are higher than the system costs. The energy savings result from the variation of the energy prices. For the HOEP pricing, this variation is relatively high but its absolute value is not that much and consequently the achieved savings, by this little absolute variation, are not able to cover the annual system cost of the ESS for a household. Considering an industrial large scale production of the ESS other rules due to much lower system costs may apply. For the TOU pricing, the absolute difference between the daily low and high prices is better, but due to many holidays and weekends the daily variation is not significant since $65.6 \%$ of the hours are priced at the minimum.

\subsection{Solar PV Systems}

It is found that by considering the solar system with TOU pricing, for buying and selling, the breakeven point could be reached for the average Ontario household, where the sold and saved energy, due to the in-house production, could cover the solar-system costs, however with HOEP pricing the system cost take over.

\subsection{Combination ESS + Solar PV System}

The combination of ESS and solar PV systems unites all the advantages of both systems however the costs are increasing to high values. Therefore practical related market conditions need to be available.

\subsection{Experience in Germany}

Based on the related experience in Germany, which has similar conditions for solar systems, it can be seen that there are a lot of installed solar PV systems and they run with profit. This is due to the fact that in Germany, renewable energies are receiving subvention. The generated energy by solar PV 
panels which fed into the grid is paid well. The price per $\mathrm{kWh}$, an individual gets, depends on the year of installation but after that it is fixed over 20 years. For solar PV systems built in the year 2018 the price is in the range of about $0.12 € / \mathrm{kWh}(0.18$ $\mathrm{CAD} / \mathrm{kWh}$ ) but back to year 2000 it started at over 0.50 $€ / \mathrm{kWh}(0.75 \mathrm{CAD} / \mathrm{kWh})$. After 20 years of installation, the paid energy price will follow the current market price which would correspond to the European equivalent of the HOEP. It should be also mentioned that the mean energy price for a normal household is about double of the Canadian price.

\section{Conclusions}

This paper presented some economic investigations of the integration the solar PV panels with the energy storage systems based on a case study. It is found that the ESS systems could be profitable if the annual energy savings, mainly from the variation of the energy prices, are higher than the system costs. With TOU pricing the breakeven point could be reached however with HOEP pricing the system cost take over. Therefore, the integration of solar photovoltaic panels with energy storage systems could be an advantage depending on the market conditions.

Under the current market conditions, the application of standalone ESS systems is not efficient however with the integration with solar PV systems considering some changes in market conditions, they might be applicable. Furthermore, if the buy price of the energy from the grid is higher than the sell price from the self ESS systems, in combination with a solar PV systems, could make profit. Advanced optimization and load distribution algorithms could develop the application. The future adaption of the technology might increase the economic feasibility. As done in many parts in Europe, the subventions of solar PV systems changed the economic feasibility drastically.

\section{Acknowledgements}

The authors would like to thank V. Omelianov for his support at the beginning of this work.

\section{References}

[1] L. Zhang and X. Xiong, "The effects of a backup battery and a rooftop PV system on the comfort and cost of a smart home with flexible loads and an electrical vehicle," Annual Connecticut Conference on Industrial Electronics, Technology \& Automation (CT-IETA), 2016, pp. 1-7.

[2] A. Lorestani, M. M. Ardehali and G. B. Gharehpetian, "Optimal resource planning of smart home energy system under dynamic pricing based on invasive weed optimization algorithm," Smart Grids Conference (SGC), 2016, pp. 1-8.

[3] P. Medina, A. W. Bizuayehu, J. P. S. Catalão, E. M. G. Rodrigues and J. Contreras, "Electrical Energy Storage
Systems: Technologies' State-of-the-Art, Techno-economic Benefits and Applications Analysis," 47th Hawaii International Conference on System Sciences, 2014, pp. 2295-2304.

[4] V. Omelianov and M. F. Abdel-Fattah, "Energy storage systems integration with household: A case study of average Ontario household using lead acid battery, " 2017 Saudi Arabia Smart Grid (SASG), Jeddah, 2017, pp. 1-6.

[5] F. Kazhamiaka, C. Rosenberg, and S. Keshav, Practical strategies for storage operation in energy systems: design and evaluation, IEEE Transactions on Sustainable Energy, vol. 7, iss. 4, Oct. 2016, pp. 1602-1610.

[6] X. Zhu, J. Yan, and N. Lu, A graphical performance-based energy storage capacity sizing method for high solar penetration residential feeders, IEEE Transactions on Smart Grid, vol. 8, iss. 1, Jan. 2017, pp. 3-12.

[7] P. Zhao, H. Wu, C. Gu, and I. Hernando-Gil, Optimal home energy management under hybrid photovoltaic-storage uncertainty: a distributionally robust chance-constrained approach, IET Renewable Power Generation, vol. 13, iss. 11, 2019, pp. 1911-1919.

[8] M. Rahmani-Andebili, and H. Shen, Price-controlled energy management of smart homes for maximizing profit of a GENCO, IEEE Transactions on Systems, Man, and Cybernetics: Systems, vol. 49, iss. 4, April 2019, pp. 697-709.

[9] The official Environment and Climate Change Canada data-Data Download for Ottawa (Kanata-Orléans). Available at: https://ottawa.weatherstats.ca/download.html

[10] The Independent Electricity System Operator (IESO)-Data Directory (webpage). Available at: http://www.ieso.ca/power-data/data-directory

[11] J. F. Peters, M. Baumann, B. Zimmermann, J. Braun, and M. Weil, "The environmental impact of Li-Ion batteries and the role of key parameters-A review," Renewable and Sustainable Energy Reviews, Volume 67, 2017, pp. 491-506.

[12] S. Dhundhara, Y. P. Verma, and A. Williams, "Techno-economic analysis of the lithium-ion and lead-acid battery in microgrid systems," Energy Conversion and Management, Volume 177, 2018, pp. 122-142.

[13] M. Baumann, J. F. Peters, M. Weil, and A. Grunwald, " $\mathrm{CO}_{2}$ Footprint and Life-Cycle Costs of Electrochemical Energy Storage for Stationary Grid Applications," Energy Technol. 2017, 5, pp. 1071-1083.

[14] M. Baumann, J. Peters, M. Weil, C. Marcelino, P. Almeida and E. Wanner, "Environmental impacts of different battery technologies in renewable hybrid micro-grids," 2017 IEEE PES Innovative Smart Grid Technologies Conference Europe (ISGT-Europe), Torino, 2017, pp. 1-6.

[15] Average Cost of Solar Panels in Canada 2018. Available at: https://solarpanelpower.ca/cost-solar-panels-canada/\#watt, (visited on 28.12.2018).

[16] How Solar Power Works in Canada. Available at: https://solarpanelpower.ca/how-solar-power-works-canada/, (visited on 29.12.2018). 